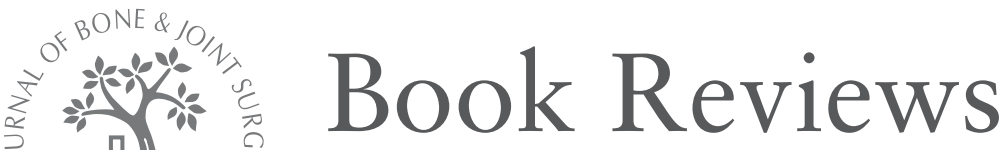

(C)British Editorial Society of Bone and Joint Surgery doi:10.1302/0301-620X.88B11.18601 \$2.00

J Bone Joint Surg [Br] 2006;88-B:1547.

\section{The evolution of surgical instruments: an illustrated history from ancient times to the Twentieth Century By J. Kirkup}

Pp. 507. California: Norman Publishing, 2006. ISBN: 0-930405-86-2. \$275.00.

Great teachers are able to develop a student's interest in a subject and inspire devotion to it, while the greatest can create that interest where it did not previously exist. I defy any colleague to open this book, browse through its heavily-illustrated pages and not be drawn into reading the text. This is a volume of exceptional beauty and denselypacked information. Mr Kirkup has identified an important aspect of a surgical education and produced a lively, fascinating treatise, the reading of which will generate respect for our surgical forebears and admiration for the heroism of their patients.

The title is well chosen. The author presents evolution rather than history, suggesting an ongoing process based upon pragmatism, and in so doing, presents the evolution of surgery itself. The book is divided into chapters covering prehistory and archaeology, structure and form, materials and applications. The development of the common surgical tools, such as forceps, scissors, probes and clamps is followed meticulously and shows us that they are all continuously changing for functions yet to be defined.

History is not the usual source for surgical instruction, except perhaps to learn what not to do, but this book, a bestiary of operating images, will excite and fascinate. Inevitably the pathology for surgical treatment in ancient times was limited, much being trauma or genitourinary, but John Kirkup has included all manner of instruments, some for the strangest of procedures. He invites us to look kindly upon the myriad tools for the purpose of shedding blood, and then mercifully, even more for stemming haemorrhage. He covers fully the rivalry between the famous names from the turn of the last century, still attached to artery forceps - Dunhill, Mayo, Kocher, Moynihan, and Spencer Wells who recommended his snap in order "to replace the pinching assistant's finger and thumb." The chapter on the tools for closing a wound is a lesson in gentle precision, on how to close a wound, and then again, when and why not to do so.

The application of certain classic pieces of equipment is shown in drawings of their use; for example, the picture of the self-deliverable enema apparatus is a buttock-clenching image. Kirkup has added innumerable comments upon the pictures which would not normally occur to the average voyeur. For example, the reason why amputation of the leg was usually performed with the patient in the upright sitting position was that he was more likely to lose consciousness quickly and thereby achieve relief.

To study the developing shapes of ancient instruments is to understand the basis for surgical intervention. What leaps off these pages is exactly what the surgeon intended and how it would be performed most expeditiously. Each curve of edge and handle states how force was to be used, or when accuracy and precision were necessary. John Kirkup's viewpoint is that of a surgeon rather than that of an archaeologist, so his interpretation is patient-orientated. The non-medical reader's reaction to the artistic depictions of ancient operating theatre drama may generate either horror or laughter; no one will remain unmoved.

It is natural in a book which is so richly illustrated for artistic appreciation to be central to a review. Indeed it would not be possible for the subject to be addressed without pictures, and here they are of exceptional quality. Through them can be seen the basis and background of modern surgery. The decoration of instruments, often in pre-Raphaelite style, carried more than functional importance. In such a scene their embellishment doubtless inspired some measure of confidence. It is interesting that the very last piece of decoration to be stripped, from both instruments and implants, is the name of the manufacturer!

It is clear that this has been one of John Kirkup's lifelong hobbies. It must have been a difficult decision to know when to stop. He makes no claim that this will be a definitive work, but there is little doubt that it will be a historical treasury, saying as much about surgery in the past few hundred years as many more literary accounts.

Regular readers of these Book Review pages will have noticed a common final sentence of a review to recommend that 'although each reader will probably not require a personal copy, such and such a volume should be made available for reference in the hospital library.' This does not apply to this book. It will be on the treasured shelves in the homes of every surgeon who is both dedicated and devoted to his art.

To order this book, please email orders@jnorman.com or fax to +1 4152762317.

M. Laurence

\section{The bionic human: health promotion for people with implanted prosthetic devices}

\section{Edited by F. E. Johnson and K. S. Virgo}

Pp. 704. New Jersey: Humana Press, 2006. ISBN: 0-89603-959-5. \$175.00.

It is not clear as to whom this rather tabloid title is addressed. Its orthopaedic content hardly justifies inclusion in our Book Review pages. And yet, given time to step back from our specialty, this is a subject which deserves some attention. It is no longer good enough to be single-minded in honing our craft. If we are to fight for it, we must keep informed about the whole of the economic healthcare scene.

The cover picture depicts a skeleton with a great variety of rather old-fashioned joint prostheses; but this is deceptive. The text does not refer to orthopaedic implants until page 655 , and then provides only 30 pages of rather elementary cover. Precedence is given inter alia to implants into the breast, to replacement of the optical lens, various arteries, teeth, a number of functional organs including the heart and the penis. Certainly the private sector has its own agenda. The subject of rationing cannot long be avoided in the NHS. It has to include some value judgements. We should not forget that one of our past masters, Charnley, was once nominated for the Nobel Prize for Medicine.

Some complications and disappointments are discussed, and an attempt is made to lump together the management of infection in a disparate collection of specialties. A substantial section addresses the ethical, sociological, legal and economical aspects. Orthopaedic surgeons have enough to worry about, but it is interesting to see where and how such a large part of the healthcare cake may be consumed.

M. Laurence 